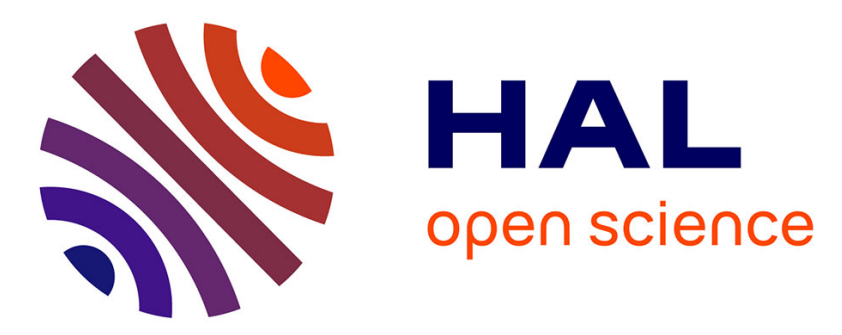

\title{
Influence of oxidizing and Nitriding parameters on nitrogen concentration of electrical steels
}

\author{
S. Jégou, M. Teodorescu, L. Barrallier, F. Guittonneau
}

\section{To cite this version:}

S. Jégou, M. Teodorescu, L. Barrallier, F. Guittonneau. Influence of oxidizing and Nitriding parameters on nitrogen concentration of electrical steels. Materials Characterization, 2021, 182, pp.111529. 10.1016/j.matchar.2021.111529 . hal-03403350

\section{HAL Id: hal-03403350 \\ https://hal.science/hal-03403350}

Submitted on 26 Oct 2021

HAL is a multi-disciplinary open access archive for the deposit and dissemination of scientific research documents, whether they are published or not. The documents may come from teaching and research institutions in France or abroad, or from public or private research centers.
L'archive ouverte pluridisciplinaire HAL, est destinée au dépôt et à la diffusion de documents scientifiques de niveau recherche, publiés ou non, émanant des établissements d'enseignement et de recherche français ou étrangers, des laboratoires publics ou privés. 


\section{Materials Characterization}

\section{Influence of Oxidizing and Nitriding Parameters on Nitrogen Concentration of Electrical Steels \\ --Manuscript Draft--}

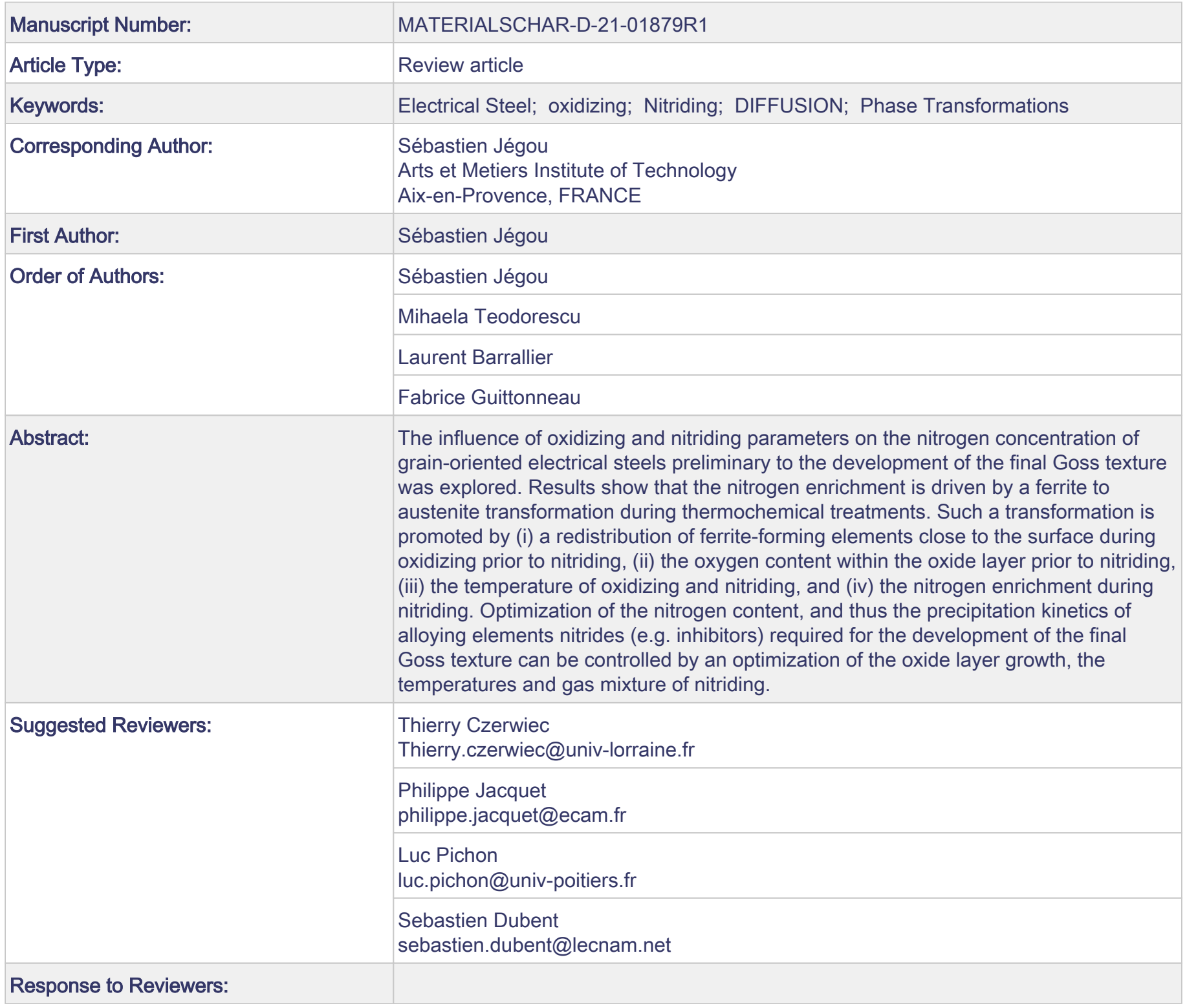




\section{Highlights}

- The nitrided layer of electrical steels is coincident with the oxide layer

- The nitrogen content increases with the decrease of the nitriding temperature

- Oxidizing induces a redistribution of heavy elements ( $\mathrm{Si}, \mathrm{Cr}, \mathrm{Mn}, \mathrm{Al})$

- The nitrogen enrichment is driven by a ferrite to austenite transformation

- The austenite transformation is promoted by diffusing $\mathrm{Si}, \mathrm{O}$ and $\mathrm{N}$ 


\title{
Influence of Oxidizing and Nitriding Parameters on Nitrogen Concentration of Electrical Steels
}

\author{
S. Jégou ${ }^{1}$, M. Teodorescu ${ }^{2}$, L. Barrallier ${ }^{1}$, F. Guittonneau ${ }^{1}$ \\ ${ }^{1}$ Arts et Metiers Institute of Technology, MSMP, HESAM Université, F-13617 Aix-en-Provence, \\ France \\ ${ }^{2}$ thyssenkrupp Electrical Steel UGO, Isbergues, France \\ sebastien.jegou@ensam.eu, Mihaela.Teodorescu@thyssenkrupp.com,_laurent.barralier@ensam.eu, \\ fabrice.guittonneau@ensam.eu
}

Corresponding author: S.Jégou, sebastien.jegou@ensam.eu, Arts et Metiers Institute of Technology, MSMP, HESAM Université, F-13617 Aix-en-Provence, France

\begin{abstract}
The influence of oxidizing and nitriding parameters on the nitrogen concentration of grain-oriented electrical steels preliminary to the development of the final Goss texture was explored. Results show that the nitrogen enrichment is driven by a ferrite to austenite transformation during thermochemical treatments. Such a transformation is promoted by (i) a redistribution of ferrite-forming elements close to the surface during oxidizing prior to nitriding, (ii) the oxygen content within the oxide layer prior to nitriding, (iii) the temperature of oxidizing and nitriding, and (iv) the nitrogen enrichment during nitriding. Optimization of the nitrogen content, and thus the precipitation kinetics of alloying elements nitrides (e.g. inhibitors) required for the development of the final Goss texture can be controlled by an optimization of the oxide layer growth, the temperatures and gas mixture of nitriding.
\end{abstract}

\section{Keywords}

Electrical steel, oxidizing, nitriding, diffusion, phase transformations

\section{Introduction}

The evolution of environmental concerns in the last decay has been pushing electrical conversion systems to new developments and challenging optimizations. In case of electrical transformers, a complex process route leads to decrease core lost and increase the magnetic permeability [1-3]. A succession of hot and cold rolling, thermochemical surface and heat treatments have been optimized to manufacture so called "grain-oriented" (GO) electrical steels. The quality of the final crystallographic texture, e.g. Goss texture, directly drives the electrical performances. Goss texture, $\{110\}<001>$, develops due to an abnormal grain growth thanks to, at least, the presence of grain-growth inhibitors within the microstructure such as $\mathrm{MnS}$ precipitates and alloying elements nitrides $\mathrm{MN}(\mathrm{M}=\mathrm{Si}, \mathrm{Al}$, 
Cr...) [4-8]. Optimizing such a complex process route appears time consuming, costly and complex, especially because the magnetic properties can only be measured when the entire process route was accomplished.

In case of $\mathrm{MN}$ inhibitors, three nitriding treatments have been optimized to promote such a precipitation: (i) inherent nitriding from nitrogen available in the materials from casting [5], (ii) equilibrium nitriding from reaction of dinitrogen $\mathrm{N}_{2}$ during the last heat treatment during which the Goss texture develops [10-11] and (iii) non-equilibrium nitriding from reaction of ammonia $\mathrm{NH}_{3}$ inline after the oxidizing treatment [8-9]. Inherent and equilibrium nitriding do not promote a high enough adsorption of nitrogen by the steel, leading to non-optimized fraction of inhibitors to promote the Goss texture [9]. Development of the non-equilibrium nitriding treatment regarding the magnetic properties has been reached identifying the acceptable range of nitrogen concentration for an efficient abnormal grain growth, the corresponding temperature of nitriding, and the range of ammonia to dihydrogen ratio to use in order to get satisfying precipitation of inhibitors [12-13]. Prior to nitriding, oxidizing aims decarburizing electrical steels as well as the later growth of an insulated layer (glass film) [14-16]. Studies were carried out on the structure of the oxides' layer and on influence of process parameters on oxides' layer properties. [17-18]. However, details about the nitriding kinetics, and most of all on the influence of the oxide layer on nitriding kinetics, and thus on the nitrogen enrichment and on control of the precipitation of inhibitors are missing in the literature [19-25].

The present work aims to study the influence of oxidizing and nitriding parameters on the nitrogen adsorption and diffusion kinetics right before the development of the final Goss texture.

\section{Experimental}

\subsection{Materials}

The material is a silicon iron-based alloy used for grain-oriented electrical steel. Samples of 30x30x0.2 $\mathrm{mm}^{3}$ were provided by thyssenkrupp Electrical Steel for investigations. Sensitive analysis of annealing parameters was performed through laboratory trails and experimental measurements. Conditions of oxidizing are chosen to promote both oxidizing and decarburizing in a single step. The dew point ( $T_{D P}$ controlled by $\mathrm{H}_{2} \mathrm{O}$ vapour and a chilled mirror hygrometer) and temperature $\left(T_{O}\right)$ of oxidizing prior to nitriding stage were varied from 40 to $70^{\circ} \mathrm{C}$ and from $840^{\circ} \mathrm{C}$ to $900^{\circ} \mathrm{C}$ respectively. Samples have then been nitrided in a gas mixture using $\mathrm{H}_{2}, \mathrm{~N}_{2}$ and $\mathrm{NH}_{3}$, at various temperatures $\left(T_{N}\right)$, from $770^{\circ} \mathrm{C}$ to $930^{\circ} \mathrm{C}$. The nitriding potential (defined by the fraction of both $\mathrm{NH}_{3}$ and $\mathrm{H}_{2}$ ) was kept fixed to a usual low value used for electrical steels according to industrial practice because of the complexity to control low nitriding potential in industrial conditions especially at such high temperature (higher than $600{ }^{\circ} \mathrm{C}$ ). Cases without nitriding were as well considered in order to dissociate the various parameters influences. The studied GO samples had the following main chemical composition $3.1 \mathrm{wt} . \% \mathrm{Si}, 0.028$ wt.\%Al, 0.15 wt.\% Mn, 0.0095 wt.\% N and almost no C, the 
The microstructure was observed by scanning electron microscopy (SEM) using a Jeol JSM-7001F microscope and backscatter electrons mode. Prior to observations, ionic polishing (Ar+ ions, $4 \mathrm{kV}$ ) was performed on each transversal cut using a Jeol Cross Section Polisher.

Chemical analysis was carried out by glow discharge optical emission spectroscopy (GDOES) using a Profiler 2 device from Horiba. The surface of interest was around $4 \mathrm{~mm}$ in diameter parallel to the surface of the sheet. The RF power, gas pressure and time of analysis were set to $35 \mathrm{~W}, 680 \mathrm{~Pa}$ and $300 \mathrm{~s}$ respectively, that corresponds to a depth of erosion of approximatively $15 \mu \mathrm{m}$. Errors on chemical analysis are expected to be less than $10 \%$, and were less than 2 and $1 \%$ for nitrogen and silicon respectively on a standard.

X-ray diffraction phase analyses were performed at room temperature using a Siemens D500 diffractometer, an Elphyse linear detector and the chromium $K \alpha$ radiation. The diffraction angle $2 \theta$ was varied from 40 to $140^{\circ}$, that corresponds to a penetration depth of 2 to $6 \mu \mathrm{m}$ in the ferritic matrix.

\subsection{Thermodynamics calculations}

Thermodynamics calculations were performed using Thermo-Calc version 2021a, TCFE Steels/Fealloys database version 07 and TC-Python [26].

\section{Results}

\subsection{Microstructure observation}

102 Figure 1 shows an example of the microstructure after oxidizing and nitriding observed by SEM using 103 the backscattered electron mode. The outer surface is characterized by an oxide layer of 104 approximatively $2 \mu \mathrm{m}$ thickness. The oxide layer is divided in two sublayers, one subscale at the 105 extreme surface of nearly $0.5 \mu \mathrm{m}$ thickness composed of $\mathrm{Fe}_{2} \mathrm{SiO}_{4}$ and $\mathrm{FeO}$ oxides and one of 106 approximatively $1.5 \mu \mathrm{m}$ composed of globular followed by lamellar $\mathrm{SiO}_{2}$ oxides [27]. All the samples present similar type of composition, but their distribution, volume fraction and inner properties could be different depending on the process parameters. The detailed analysis of the oxides' layer components and their properties is not the main focus of this paper, the related results will be part of another paper.

\subsection{Chemical analysis}

113 Oxygen and nitrogen in-depth profiles were obtained from GDOES analysis. Figure 2 gives a

114 comparison of contents prior to thermochemical treatments, after oxidizing, and with and without gas

115 nitriding. The effective depth of oxygen diffusion is approximatively $2.5 \mu \mathrm{m}$. The oxygen content is 
116 maximum at the extreme surface and then decreases, following an internal oxidation diffusion

117 behaviour, to reach a null concentration at $2.5 \mu \mathrm{m}$ below the surface in agreement with the SEM

118 observations given on Figure 1 for this particular case. The diffusion of nitrogen atoms tends to make

119 the diffusion process of oxygen atoms to continue during nitriding. The nitrogen content in-depth

120 profile exhibits a non-obvious evolution as a function of the depth. It is maximum at the extreme

121 surface, decreases to a minimum of nearly $0.65 \mathrm{wt} . \%$ at a depth of $0.5 \mu \mathrm{m}$, increases up to $0.8 \mathrm{wt} . \%$ at

$122 \quad 1.0 \mu \mathrm{m}$ depth before abruptly decreasing toward the core content (below $0.03 \mathrm{wt} . \%$ according to the 123 sensitivity of present GDOES analysis). The effective diffusion depth of nitrogen atoms is in 124 agreements with the one of oxygen. The nitrogen content in the oxide layer highly overestimates the 125 content within the final product that gives a good secondary recrystallization [12].

126 The affected depth by oxygen atoms increases when the dew point $\left(T_{D P}\right)$ and oxidizing $\left(T_{O}\right)$ 127 temperature increase (Figures 3 and 4). The evolution of the content of oxygen as a function of the 128 depth are all similar, characterized by a maximum fraction close to the extreme surface that decreases 129 to a null content within the core. As previously, nitrogen atoms are largely located through the entire 130 oxide layer. The higher the temperature, the lower and deeper the nitrogen enrichment is, and, the 131 lower and deeper the minimum content of nitrogen is. It reaches 0.45 and $0.35 \mathrm{wt} \%$ at a depth of $1320.65 \mu \mathrm{m}$ for a dew point and oxidizing temperatures of 70 and $900{ }^{\circ} \mathrm{C}$ respectively (Figure 3.b and 133 4.b). For low dew point $\left(40^{\circ} \mathrm{C}\right)$, no variation of nitrogen content is observed within the oxide layer. In 134 contrast, a significant decrease of the nitrogen enrichment is noted when the oxidizing temperature is 135 increasing from 840 to $900{ }^{\circ} \mathrm{C}$.

136 Figure 5 shows the influence of the nitriding temperature $\left(T_{N}\right)$ on the case depth. No significant change 137 is observed in case of the oxide layer growth. The evolution of the nitrogen content shows similar 138 profiles for all temperatures with a minimum of the nitrogen fraction at a depth of nearly $0.5 \mu \mathrm{m}$ 139 below the surface. However, increasing the nitriding temperature involves a significant decrease of the 140 nitrogen enrichment through the oxide layer. The fraction of nitrogen reaches almost $2.0 \mathrm{wt} . \%$ at $141770{ }^{\circ} \mathrm{C}$ whereas $0.5 \mathrm{wt} . \%$ are barely achieved at $930{ }^{\circ} \mathrm{C}$.

142 By considering the GDOES detection limit of nitrogen atoms (0.03 wt.\%), a diffusion zone of nitrogen 143 in $\alpha$-Fe ferrite below the oxide layer is observed to a depth of $12 \mu \mathrm{m}$. All the diffusion zones look 144 similar below the oxide layer with a nitrogen fraction ranging from 0.05 down to $0.03 \mathrm{wt} . \%$ except at 145 the low nitriding temperature of $770{ }^{\circ} \mathrm{C}$ in case of which the nitrogen fraction ranges from 0.075 down 146 to $0.03 \mathrm{wt} . \%$ (Figure 5.b).

147 One objective of oxidizing prior to nitriding is to decarburize the sample in order to achieve a 148 minimum content required to maximize the abnormal secondary recrystallisation. Figure 6 gives 149 examples of the carbon content in-depth profiles. It is observed that the decarburization of the core 150 material is effective ( 0.04 down to $0.02 \mathrm{wt} . \%)$ whereas it induces a non-negligible enrichment of 151 carbon in the oxide layer for all samples. According to the affected depth, such enrichment may be 152 attributed to the presence of $(\mathrm{Fe}, \mathrm{Mn})_{2} \mathrm{SiO}_{4}$ and $\mathrm{FeO}$ close to the surface in the oxide layer (Figure 1). 
Despite the GDOES detection limit of carbon (from 0.003 to $0.01 \mathrm{wt} . \%$ ), these measurements must be considered with precautions because of possible pollution of the surface due to cleaning for instance. More investigations are required to address the carbon enrichment of the oxide layer during oxidizing.

156 The chemical composition of some alloying elements is given on Figure 7 and 8 as a function of the depth below the surface and the temperatures of oxidizing and nitriding respectively. The same complex tendency as a function of the depth below the surface is observed for all elements. All elements are characterized by a depletion close to the outer surface, an increase of the content followed by a depletion at greater depth. The redistribution of alloying elements is observed at more profound depth when the thickness on the oxide layer increases (Figures 3 and 4). The silicon content is almost constant within the oxide layer and higher than in the core, but some profile variations are noted mostly induced by the change in dew point. Such redistribution of alloying elements through the oxidized surface is at least influenced by the oxidizing treatments (Figure 7) and nitriding does not modify them (Figure 8).

166 Finally, the total nitrogen uptake into the oxide layer can significantly vary by a factor 4 when increasing the nitriding temperature from 770 to $930{ }^{\circ} \mathrm{C}$ (Figure 5) whereas no significant change in the redistribution of carbon nor heavy elements is observed (Figures 6 and 8).

\subsection{X-ray diffraction}

Figure 9 gives the phase analyses carried out at the surface of samples as a function of the nitriding temperature, as well as after decarburizing. Austenite is identified after nitriding but not present prior to nitriding, or in a too low volume fraction or crystallite size. The lower the nitriding temperature, the higher the volume fraction of austenite is. To complement these results, a tempering was performed, subsequent to nitriding, for one minute at the nitriding temperatures tested previously and followed by water quenching. The tempered samples confirm the presence of retained austenite at room temperature after nitriding.

\subsection{Thermodynamic calculations}

180 Figure 10 gives the Fe-Si-N-2.0wt.\%O isopleth diagrams at 750 and $950{ }^{\circ} \mathrm{C}$ and possible phase 181 transformations at a depth of nearly $0.1 \mu \mathrm{m}$. Results show that a ferrite to austenite transformation 182 may occur during oxidizing and nitriding. It is due to the depletion of silicon but also to the 183 enrichment of both oxygen and nitrogen. As a consequence, the transformation is expected to be 184 promoted close to the outer surface according to GDOES analysis. Moreover the transformation is thermally activated enabling the presence of austenite for higher Si content and thus deeper within the oxide layer.

187 Figure 11 gives the thermodynamic calculations as a function of the chemical composition of samples 188 after nitriding at three different temperatures as measured by GDOES. Results show that austenite is 189 present in the oxy-nitrided layer as deep as $1.0 \mu \mathrm{m}$. At $770{ }^{\circ} \mathrm{C}$, the nitrogen enrichment significantly 
stabilizes the austenitic phase as compared to without nitriding at the same temperature between 0.2 and $1.0 \mu \mathrm{m}$ in depth (Figure 11.c).

192 The fraction of silicon nitrides within the oxi-nitrided layer increases when the temperature of nitriding decreases and must be related to an increase of the nitrogen uptake.

194 The fraction of oxides does not depend on the nitrogen content and stay nearly unchanged when comparing samples with and without nitriding. In addition, all calculations show that the nature of the silicon oxide may change according to the temperature of both oxidizing and nitriding. Below $850{ }^{\circ} \mathrm{C}$, silicon oxides are quartz like but change to tridymite at higher temperature.

\section{Discussion}

200 Chemical characterizations of a GO electrical steel after oxidizing and nitriding show that the kinetics of nitrogen adsorption and diffusion highly depends on the oxide layer growth, on the oxygen and carbon content, on the complex redistribution of heavy elements (such as $\mathrm{Si}, \mathrm{Cr}, \mathrm{Al}, \mathrm{Mn}$ ), as well as on the temperature of the heat treatments. The nitrogen content in-depth profile exhibits a non-obvious evolution as a function of the depth, with a minimum of nitrogen within the oxide layer. The higher the temperatures of oxidizing and nitriding, the deeper the diffusion of nitrogen and the lower the maximum of nitrogen in the oxide layer are (Figures 4 and 5 respectively). Nitrogen diffusion is characterized, as mentioned, by a minimum fraction of nitrogen within the oxide layer (close to a depth of $0.5 \mu \mathrm{m}$ ), that is even more pronounced when the oxide layer is thick. The nitrogen uptake does not appear depending in first approximation on the fraction and redistribution of elements such as silicon, chromium, aluminium or manganese (Figures 7 and 8). However this observation reflects the fact that, prior to nitriding, a similar redistribution of elements between oxides and matrix is obtained, for the range of the variations of the decarburizing (oxidizing) temperature considered.

213 But any change in the silicon or aluminium redistribution between the matrix and oxides during oxidizing is obviously expected to play a role on the formation of silicon and aluminium nitrides and thus on the level of the nitrogen uptake during nitriding.

216 Chemical analyses revealed that oxidizing leads to a decrease of the carbon content within the core 217 material thanks to the decarburizing atmosphere during oxidizing, but results in a carbon enrichment 218 of the oxide layer prior to nitriding (Figure 6). Heavy elements also exhibit a complex redistribution 219 through the oxide layer prior to nitriding (Figures 7 and 8), consistent with the literature using the 220 same chemical analysis method [27]. These redistributions of already present elements are influenced 221 by the conditions of oxidizing and not affected by those of nitriding.

222 Thermodynamic calculations of temperature isopleths for given oxygen content or using compositions as measured by GDOES show that a ferrite to austenite transformation may occur within the oxide layer during nitriding (Figure 10). The higher the oxygen content and temperature, the lower the transformation point from ferrite to austenite is during nitriding. The ferrite to austenite transformation

226 is as a consequence promoted close to the surface in the oxide layer. Although the carbon fraction 
measurement may need optimization for GDOES analysis, the presence of carbon content within the oxide layer can promote such an austenitic transformation. Calculations confirm the present experimental observations of retained austenite by XRD at the surface of samples (Figure 9). 230 Austenite was also observed experimentally at the extreme surface of the oxide layer in other recent 231 works $[16,25]$. The fraction of austenite increases in agreement with the nitrogen content according to GDOES analysis and the Fe-N phase diagram [28]. Iron nitrides being more thermodynamically stable than austenite at room temperature [28], tempering after nitriding must promote the decomposition of austenite into ferrite and iron nitrides. It thus leads to no observation of austenite at room temperature by XRD. However iron nitrides were not observed by XRD that suggests a low fraction of iron nitrides or too small crystallites. More investigations are required.

237 The observation of a minimum of the nitrogen fraction in the oxide layer close to $0.5 \mu \mathrm{m}$ below the 238 surface is in agreement with the transformation zone from ferrite to austenite according to 239 thermodynamic calculations (Figure 11).

240 The thermodynamic calculations let us assume that the austenitic transformation can be in competition with the precipitation of silicon nitrides, and so, even more when the transformation point is low (Figure 10). Although the nitrogen solubility limit in austenite is much higher than in ferrite, the precipitation kinetics of alloying elements as nitrides, and so the nitrogen uptake, may be assumed 244 slower if the austenitic transformation occurs before the complete precipitation of nitrides. Moreover, 245 it has to be considered that the diffusion kinetics of nitrogen atoms in austenite is at least one hundred 246 times lower than in a ferritic matrix [29]. It thus leads to a decrease of the flow of nitrogen atoms at 247 the beginning of the oxide layer whereas the diffusion kinetics are much faster in the ferritic area at 248 greater depth.

249 As a consequence, the calculated gradient of austenite close to the surface is expected to result in a depletion of nitrogen between the low diffusion kinetic area near the surface and the fast diffusion

251 kinetics area (ferrite zone) deeper in the oxide layer. The nitrogen enrichment being slower due to the 252 austenitic transformation prior to the complete precipitation of silicon nitrides at the surface, the 253 boundary conditions for diffusion in the ferritic zone deeper in the material must also change towards 254 lower value. Therefore, it induces a lower level of nitrogen in ferrite and a slower precipitation 255 kinetics of alloying elements as nitrides deeper in the oxide layer.

256 According to thermodynamic calculations and the higher chemical affinity of both silicon and 257 aluminium with oxygen than nitrogen [30], the oxides already present before nitriding are supposed not to take part in the precipitation of silicon and aluminium nitrides.

259 Calculations show that the nature of silicon oxides could also change during nitriding function of the 260 content of both oxygen and silicon, but also depending on the temperature of oxidizing and nitriding. 261 Similarly, the nature and fraction of iron-silicon oxide at the outer surface (e.g. $(\mathrm{Fe}, \mathrm{Mn})_{2} \mathrm{SiO} 4 \mathrm{and} /$ or $262 \mathrm{FeO}$ ) may play a role on the catalytic dissociation of ammonia and the nitrogen adsorption and uptake. 
263 However present experimental results cannot conclude on any effect of such change of oxides on the

264 diffusion kinetics of nitrogen atoms during nitriding.

265 Finally, it is well known that the natural dissociation rate of ammonia $\mathrm{NH}_{3}$ into $\mathrm{N}_{2}$ and $\mathrm{H}_{2}$ gas mixture

266 increases exponentially with the temperature [31]. As a result, and considering perfect gas transfer to

267 the solid surface, the nitrogen fraction at the gas-solid interface available for adsorption into the solid

268 from the catalytic dissociation of ammonia at the solid surface naturally decreases and thus the

269 nitrogen enrichment within the oxide layer. Moreover, at the atmospheric pressure, the dissociation

270 rate of dinitrogen molecules $\mathrm{N}_{2}$ during nitriding cannot compensate the lack of nitrogen atoms from

271 the catalytic ammonia dissociation at the solid surface without increasing the pressure [31-33].

\section{5. Conclusion}

274 Influences of the conditions of oxidizing and nitriding on the nitrogen enrichment prior to the

275 development of the final Goss texture were explored in case of a grain-oriented electrical steel. The

276 nitrogen enrichment in the oxide layer can significantly overestimate the nitrogen content required for

277 the development of the final Goss texture. The nitrogen atoms are exclusively located within the about

$2782.5 \mu \mathrm{m}$ thick oxide layer after nitriding. The nitrogen diffusion kinetics through the oxide layer

279 depends on a ferrite to austenite transformation during oxidizing and nitriding. The transformation

280 point decreases with (i) the increase of the fraction of oxygen, carbon and nitrogen atoms, (ii) the

281 depletion of heavy elements very close to the outer surface and (iii) the temperature increase.

282 The nitrogen content, that leads to the optimized precipitation of inhibitors required for the

283 development of the final Goss texture and the optimum magnetic properties, is driven by the oxidizing

284 and nitriding conditions that must be involving a ferrite to austenite transformation if not controlled.

285 The nitrogen enrichment, and thus the development of inhibitors, can obviously be optimized and

286 controlled depending on the conditions of oxidizing and nitriding. It arises that optimize the nitriding

287 potential through the gas mixture $\left(\mathrm{NH}_{3}-\mathrm{N}_{2}-\mathrm{H}_{2}\right)$ could also be necessary in order to get the most

288 efficient thermochemical treatments conditions of electrical steels.

\section{Data availability}

292 The raw/processed data required to reproduce these findings cannot be shared at this time as

293 the data also forms part of an ongoing study

\section{References}

297 [1] Littmann M.F., Iron and Silicon-Iron Alloy, IEEE Transactions on Magnetics MAG-7(1) (1971) $298 \quad 48-69$ 
[2] Taguchi S., Sakakura A., Matsumoto F., Takashima K., Kuroki K., The development of grain300 oriented silicon steel with high permeability, Journal of Magnetism and Magnetic Materials 2 (1976) $301 \quad 121-131$

302 [3] Ushigami Y., Masui H., Okazaki Y., Suga Y., Takahashi N., Development of low-loss grainoriented silicon steel, Journal of Materials Engineering and Performance 5(3) (1996) 310-315

304 [4] Markuszewicz M., Groyecki J., Lassota J., Zawada A., Stability of inclusions and the formation 305 of secondary grains in silicon-iron alloys, Transactions of the Metallurgical Society of AIME 236 306 (1966) 196-200

307 [5] Fiedler H., A comparison of the use of aluminum and vanadium nitrides for making grain308 oriented silicon-iron, Journal of Applied Physics 38(3) (1967) 1098-1099

309 [6] Matsuoka T., Effect of impurities on the development of (110)[001] secondary recrystallization 310 texture in 3\% silicon iron, Transactions ISIJ 7 (1967) 19-28

311 [7] Grenoble H.E., The role of solutes in the secondary recrystallization of silicon iron, IEEE 312 Transactions on Magnetics MAG-13(5) (1977) 1427-1432

313 [8] Ushigami Y., Nakayama T., Suga Y., Takahashi N., Influence of inhibitor intensity on 314 secondary recrystallization in Fe-3\%Si alloy, Materials Science Forum 204-206 (1996) 599-604

315 [9] Takahashi N., Harase J., Recent development of technology of grain oriented silicon steel, 316 Materials Science Forum 204-206 (1996) 143-154

317 [10] Suga Y., Matsumoto F., Nakayama T., Japanese Patent, Application No.S57-165066 (1982)

318 [11] Konno T., Suga Y., Nakamura M., Komatsu H., Japanese Patent, Application No.S59-215827 319 (1984)

320 [12] Kobayashi H., Kuroki K., Minakuchi M., Yakashiro K., United States Patent 4,979,996 (1990)

321 [13] Ushigami Y., Nakayama T., Suga Y., Takahashi N., Influence of secondary recrystallization temperature on secondary recrystallization texture in Fe-3\%Si alloy, Materials Science Forum 204$323206(1996) 605-610$

324 [14] Yamazaki T., On the decarburization of silicon steel sheet, Transactions ISIJ 9 (1969) 66-75

325 [15] Block W.F., Jayaraman N., Reactions during decarburization annealing of electrical steel, 326 Materials Science and Technology 2 (1986) 22-27

327 [16] Wu X-1., Li X., Yang P., Jia Zh-w., Zhang H-1., Analysis of oxide layer structure in nitrided 328 grain-oriented silicone steel, International Journal of Minerals, Metallurgy and Materials, 26(12) $329 \quad$ (2019) 1531-1538

330 [17] Lyudkovsky G., Preban A.G., Shapiro J.M., The influence of annealing conditions on the 331 internal oxidation and magnetic properties of silicon-aluminium bearing electrical steels, Journal of 332 Applied Physics 53(3) (1982) 2419-2421

333 [18] Cesar M.G.M.M., Mantel M.J., Effect of the temperature and dew point of the decarburization 334 process on the oxide subscale of a 3\% silicon steel, Journal of Magnetism and Magnetic Materials $335 \quad 254-255(2003) 337-339$ 
336 [19] Kumano T., Haratani T., Fujii N., Effect of nitriding on grain-oriented steel bearing 337 aluminium, ISIJ International 45(1) (2005) 95-100

338 [20] Kumano T., Ohata Y., Fujii N., Ushigami Y., Takeshita T., Effect of nitriding on grain339 oriented steel bearing aluminium (the second study), Journal of Magnetism and Magnetic Materials 340304 (2006) e602-e607

341 [21] Liao Ch-Ch., Hou Ch-K., Effect of nitriding time on secondary recrystallization behaviors and 342 magnetic properties of grain-oriented electrical steel, Journal of Magnetism Materials 322 (2010) 434$343 \quad 442$

344 [22] Zeng G., Luo H., Li J., Gong J., Li X., Wang X., Experimental studies and numerical 345 simulation on the nitriding process of grain-oriented silicon steel, Acta Metallurgica Sinica 53(6) 346 (2017) 743-750

347 [23] Wen P., Luo H., Zeng G., Li J., Huang J., Yan B., In-situ measurement and numerical 348 simulation of nitriding kinetics of grain-oriented silicon steel, International Journal of Hydrogen 349 Energy 42 (2017) 10901-10910

350 [24] Vilela T.J.S., Faria Fonseca A.J., Costa Paolinelli S., Barros Cota A., Simultaneous 351 decarburizing and nitriding : effects on structure and magnetic properties of $3 \% \mathrm{Si}$ grain-oriented 352 electrical steel, REM, International Engineering Journal 71(4) (2018) 599-604

353 [25] Guo Q., Li X., Gong P., Nutter J., Rainforth W.M., Luo H., Why does nitriding of grain354 oriented silicon steel become slower at higher temperature? Steel Research International (2021) 3552000545

356 [26] Andersson J.O., Helander T., Höglund L., Shi P.F., and Sundman B., Thermo-Calc and

357 DICTRA, Computational tools for materials science, Calphad, 26 (2002) 273-312

358 [27] Sehoon Jung, Min Serk Kwon, Seung Bin Kim, Kwang Soo Shin, Characterization of 359 chemical information and morphology for in-depth oxide layers in decarburized electrical steel with 360 glow discharge sputtering, Surf. Interface Anal. 45 (2013) 1119-1128

361 [28] Wriedt H.A., Gokcen N.A., Nafziger R.H., The Fe-N (Iron-Nitrogen) System, Bulletin of 362 Alloy Phase Diagrams 8(4) (1987) 355-377

363 [29] Fast J.D., Verrijp M.B., Diffusion of nitrogen in iron, Journal of the Iron and Steel Institute 364176 (1954) 24-27

365 [30] P.J. Linstrom and W.G. Mallard, Eds., NIST Chemistry WebBook, NIST Standard Reference 366 Database Number 69, National Institute of Standards and Technology, Gaithersburg MD, 20899, 367 https://doi.org/10.18434/T4D303

368 [31] Schulz G., Schaefer H., Untersuchung der Bildungsgleichgewichte des Ammoniaks und 369 Trideuteroammoniaks, Berichte der Bunsengesellschaft für physikalische Chemie 70(1) (1966) 21-27

370 [32] Grabke H.J., Reaktionen von Ammoniak, Stickstoff und Wasserstoff an der Oberfläche von 371 Eisen I. Zur Kinetik der Nitrierung von Eisen mit $\mathrm{NH}_{3}-\mathrm{H}_{2}$ - Gemischen und der Denitrierung, 372 Berichte der Bunsengesellschaft für physikalische Chemie 72(4) (1968) 533-541 
373 [33] Grabke H.J., Reaktion von Ammoniak, Stickstoff und Wasserstoff an der Oberfläche von 374 Eisen II. Zur Kinetik der Nitrierung von Eisen mit $\mathrm{N}_{2}$ und der Desorption von $\mathrm{N}_{2}$, Berichte der 375 Bunsengesellschaft für physikalische Chemie 72(4) (1968) 541-548

376

377 


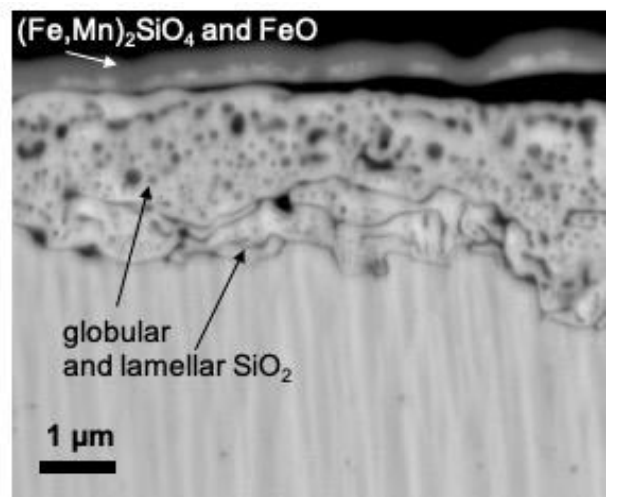

Figure 1: SEM micrography in backscattered mode of a GO electrical steel after oxidizing $\left(T_{D P}=60\right.$ $\left.{ }^{\circ} \mathrm{C}, T_{O}=870{ }^{\circ} \mathrm{C}\right)$ and nitriding $\left(T_{N}=880^{\circ} \mathrm{C}\right)$.

7 


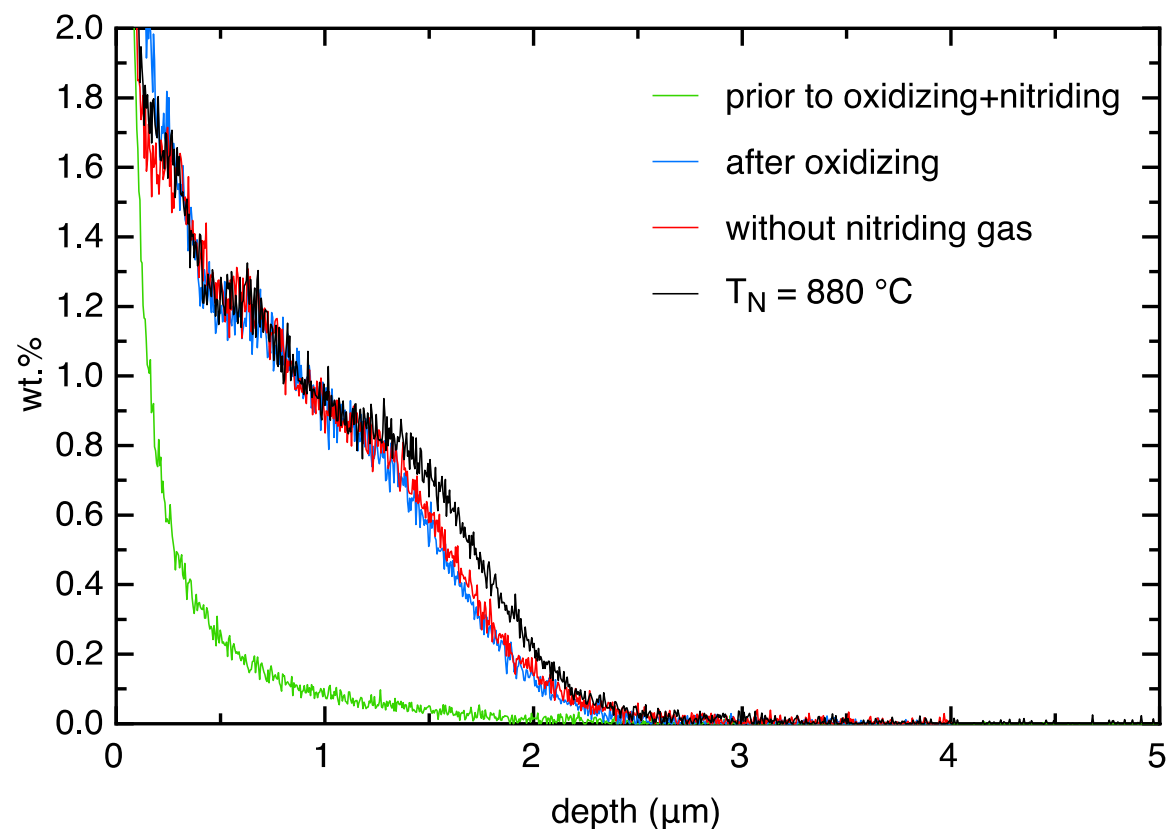

8

9

10

a. Oxygen

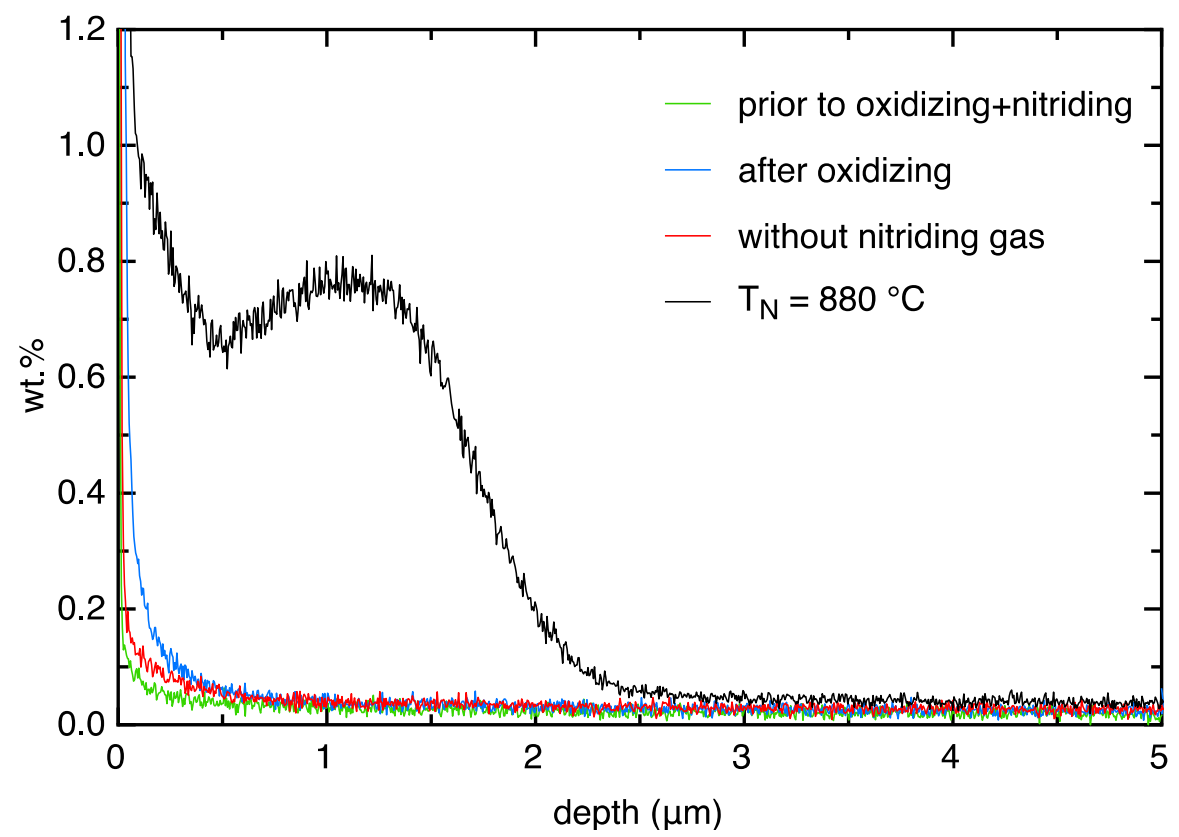

b. Nitrogen

13

14

Figure 2: GDOES chemical analyses of GO electrical steel prior to oxidizing and nitriding, after 15 oxidizing, and with and without gas nitriding. (a) oxygen and (b) nitrogen in-depth content profiles. 


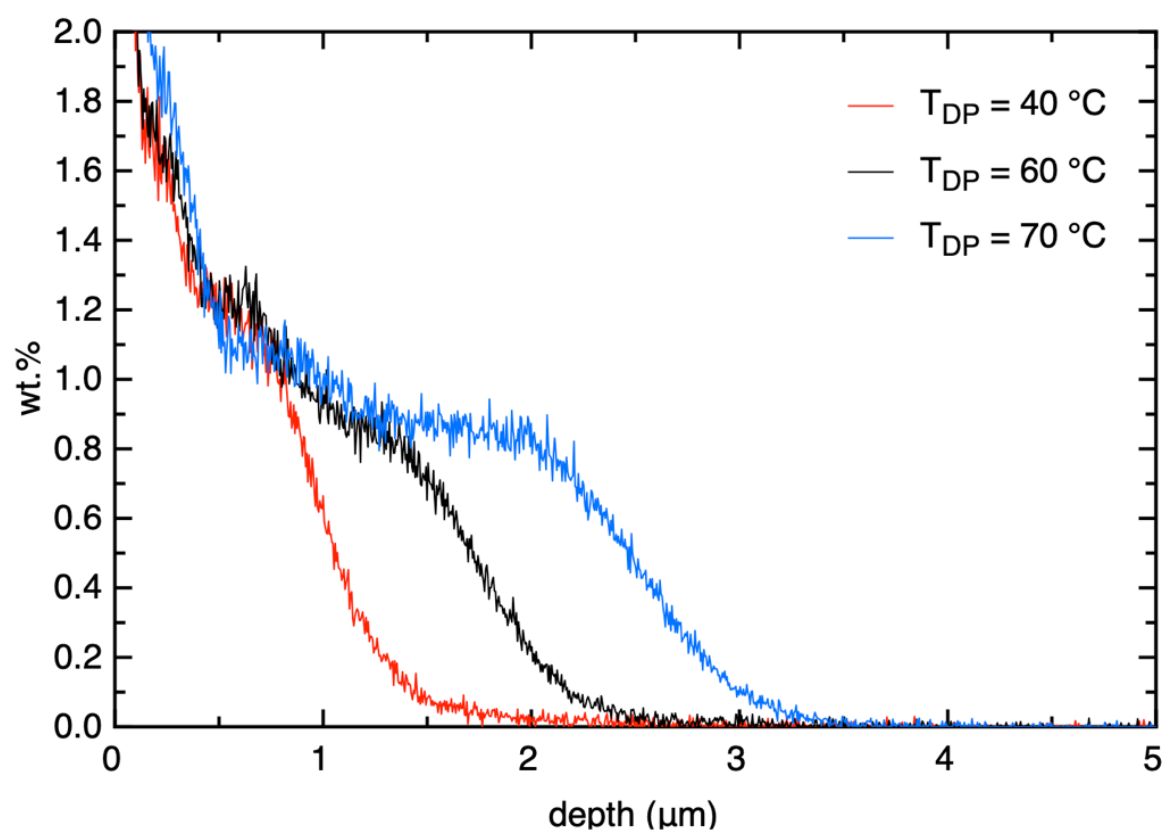

18

a. Oxygen

20

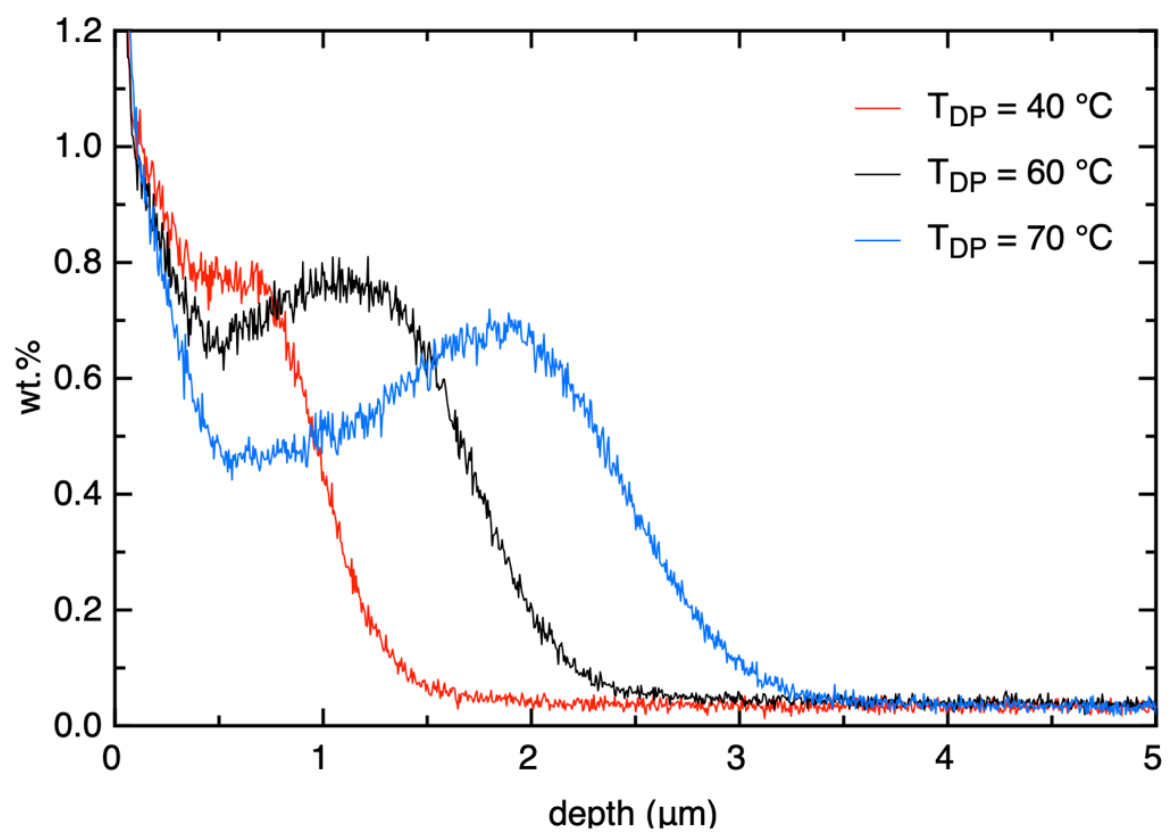

b. Nitrogen

Figure 3: GDOES chemical analyses of GO electrical steel. Influence of the dew point $\left(T_{D P}\right)$ of oxidizing on (a) oxygen and (b) nitrogen in-depth content profiles. 


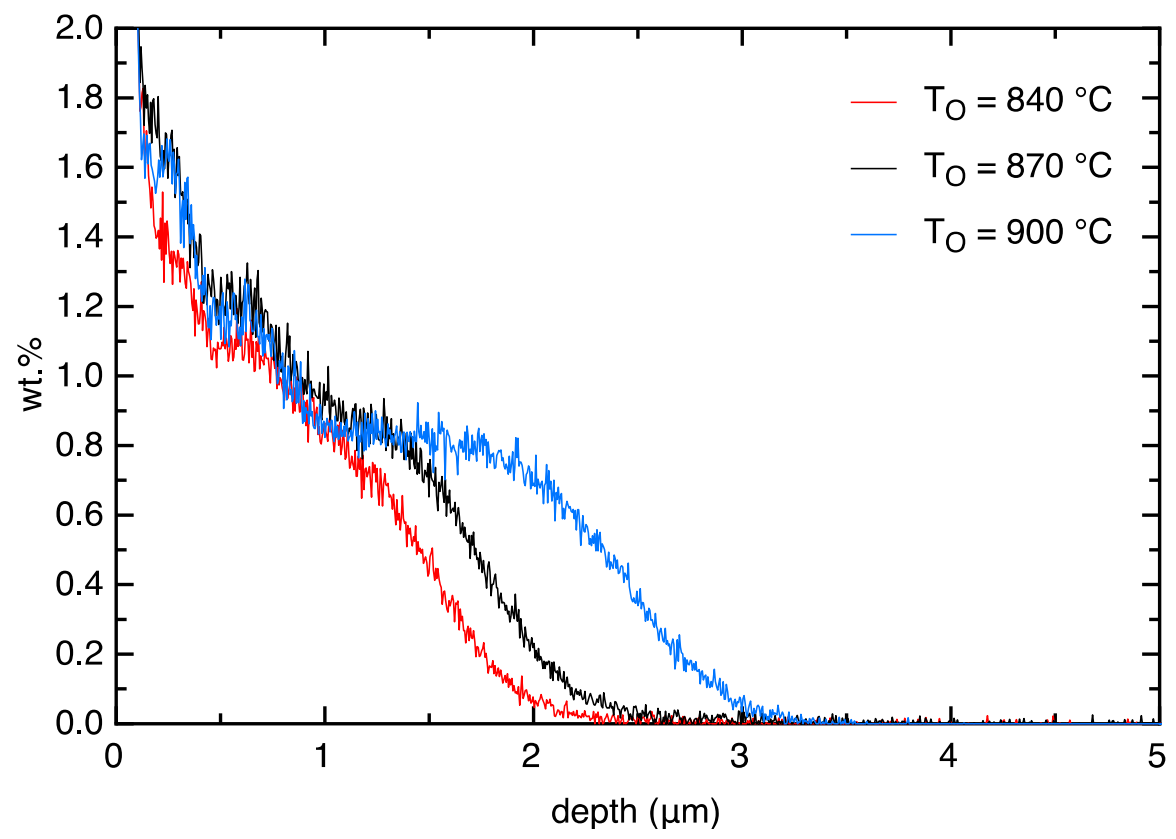

a. Oxygen

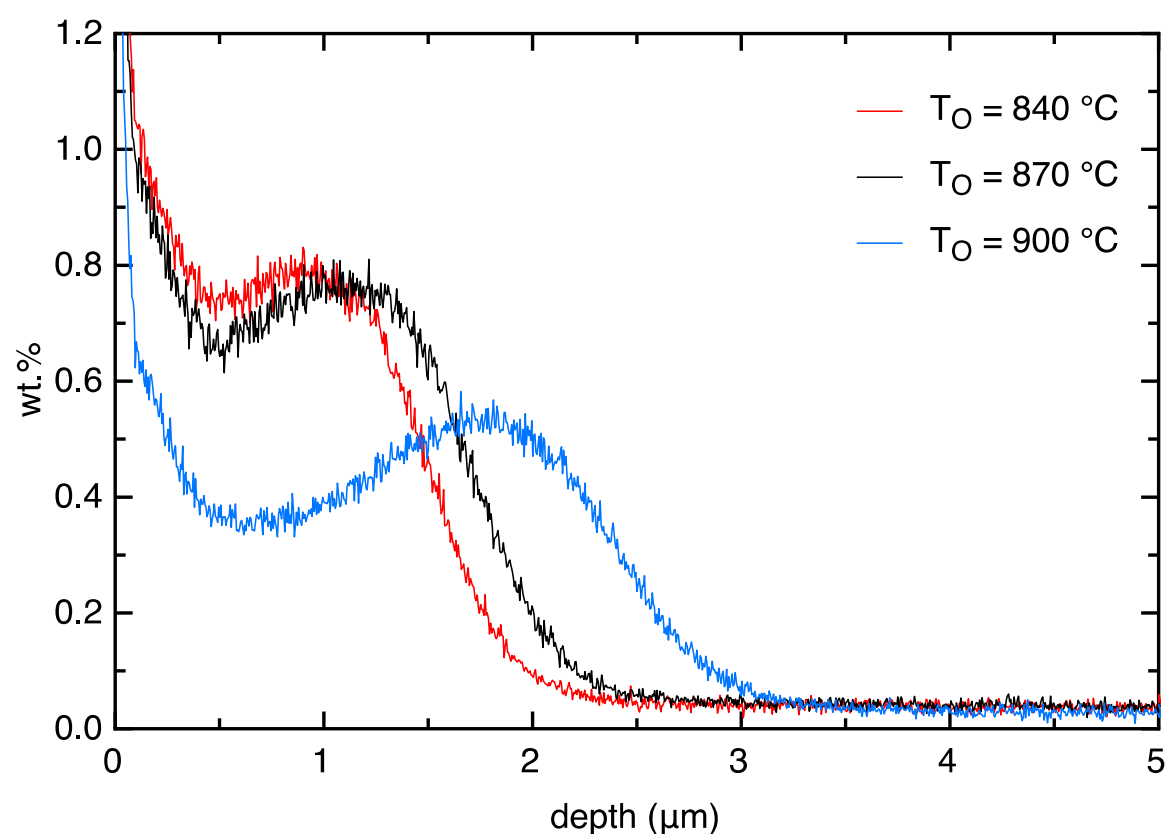

b. Nitrogen

Figure 4: GDOES chemical analyses of GO electrical steel. Influence of the oxidizing temperature $\left(T_{O}\right)$ on (a) oxygen and (b) nitrogen in-depth content profiles. 


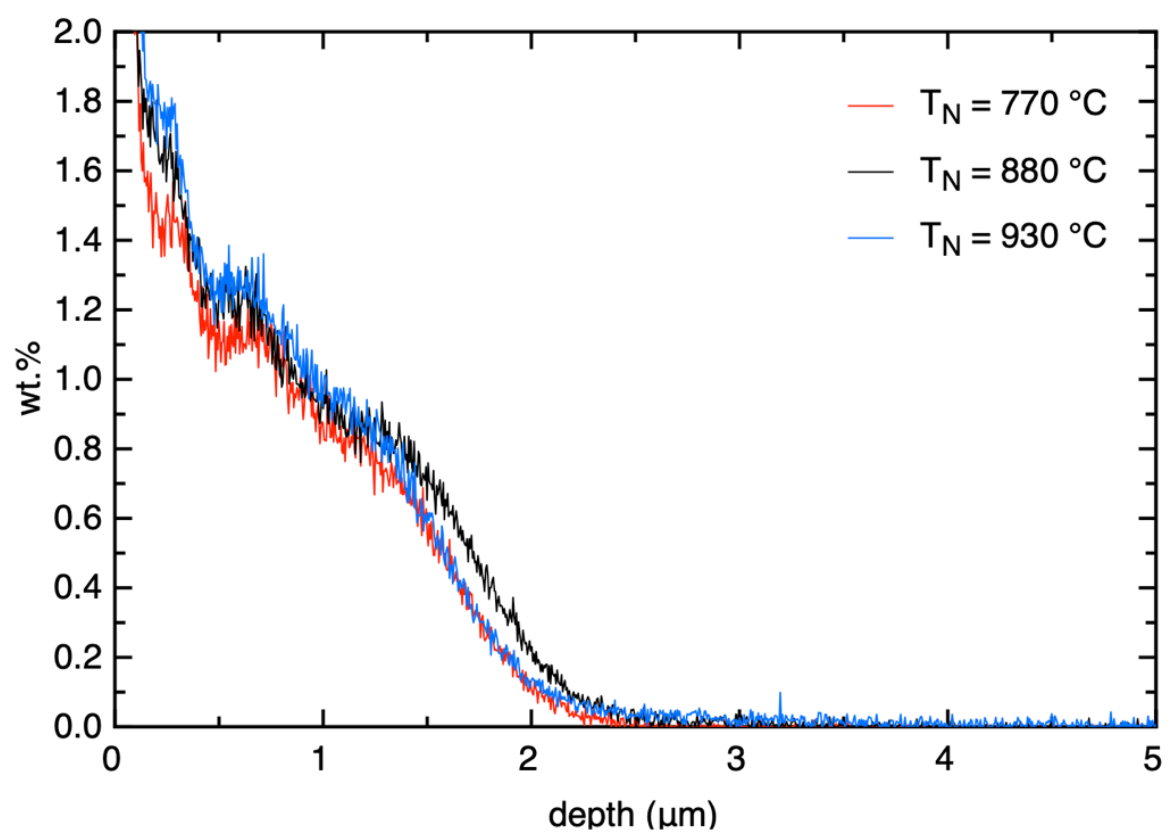

a. Oxygen

40

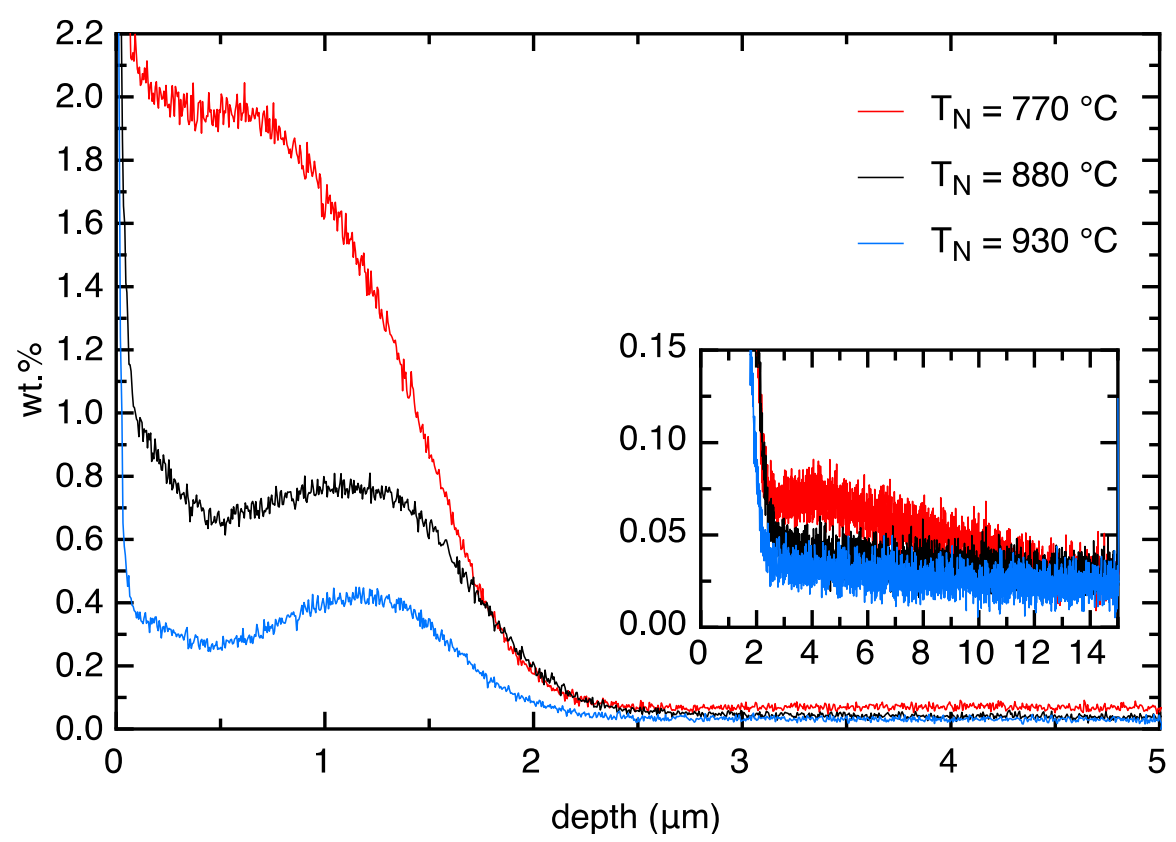

b. Nitrogen

Figure 5: GDOES chemical analyses of GO electrical steel. Influence of the nitriding temperature $\left(T_{N}\right)$ 45 on (a) oxygen and (b) nitrogen in-depth content profiles. 


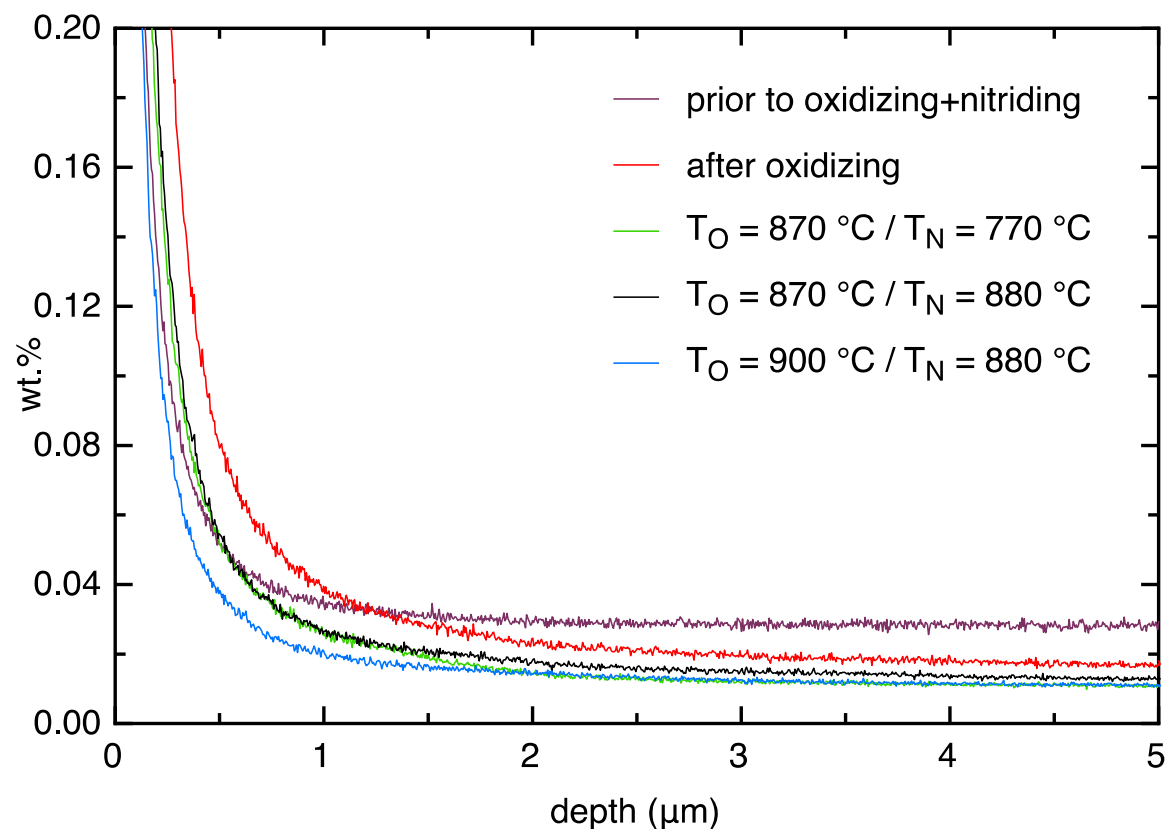

Figure 6: Carbon in-depth profiles from GDOES chemical analyses of GO electrical steel. Comparison of the carbon content at different steps of thermochemical treatments and influence of the temperature of oxidizing $\left(T_{O}\right)$ and nitriding $\left(T_{N}\right)$. 


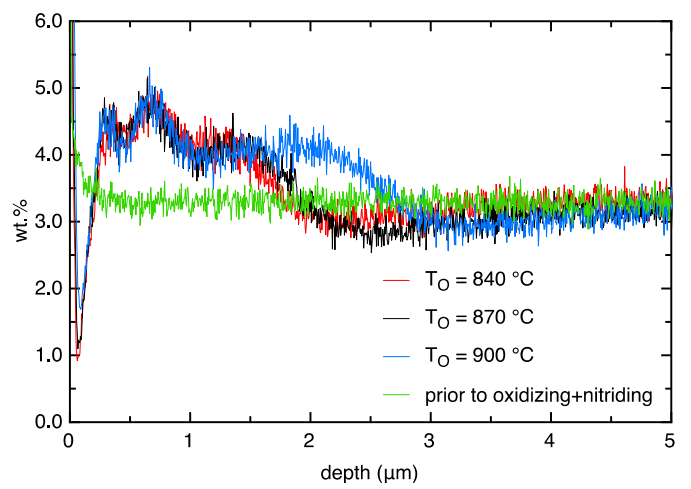

57

a. Silicon

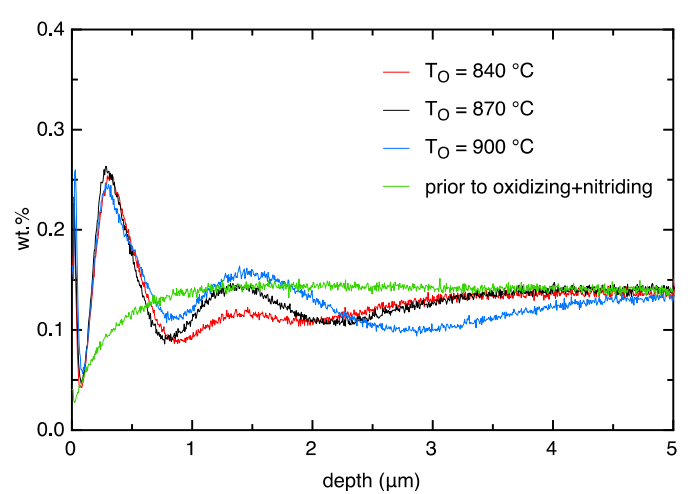

b. Chromium

60

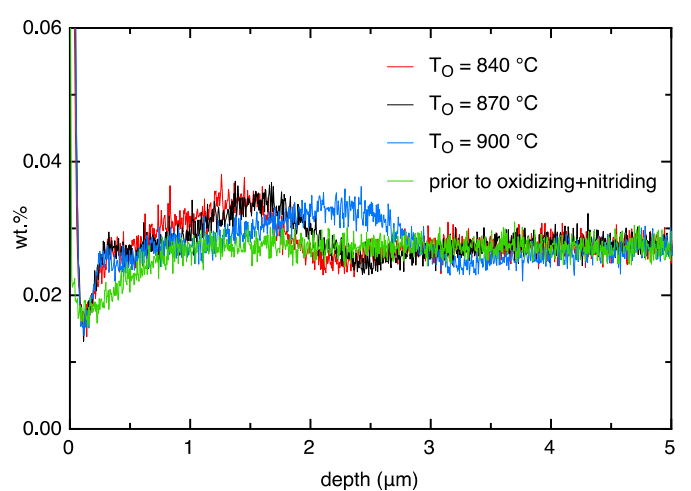

61

62

c. Aluminium

63

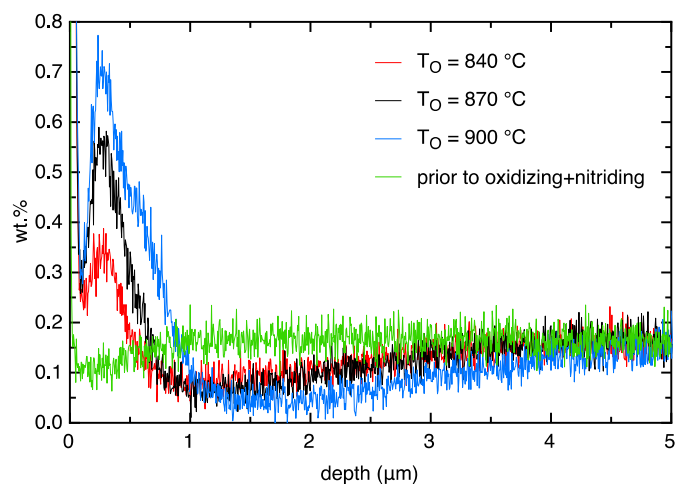

d. Manganese

Figure 7: GDOES chemical analyses of GO electrical steel. Influence of the oxidizing temperature 68 ( $T_{O}$ ) on (a) silicon, (b) chromium, (c) aluminium and (d) manganese in-depth content profiles. 


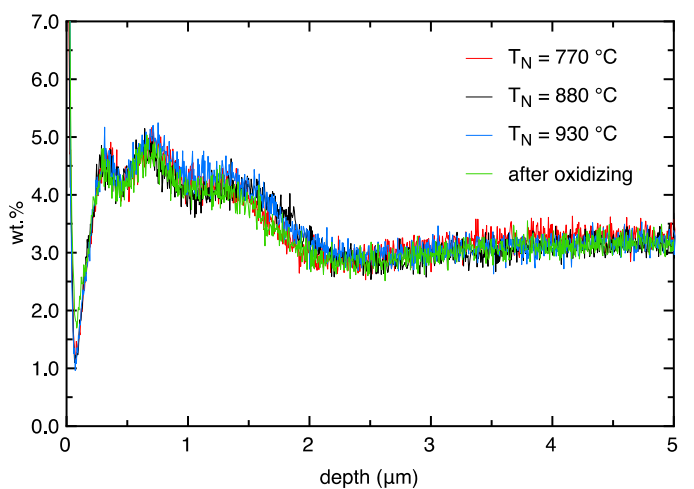

a. Silicon

71

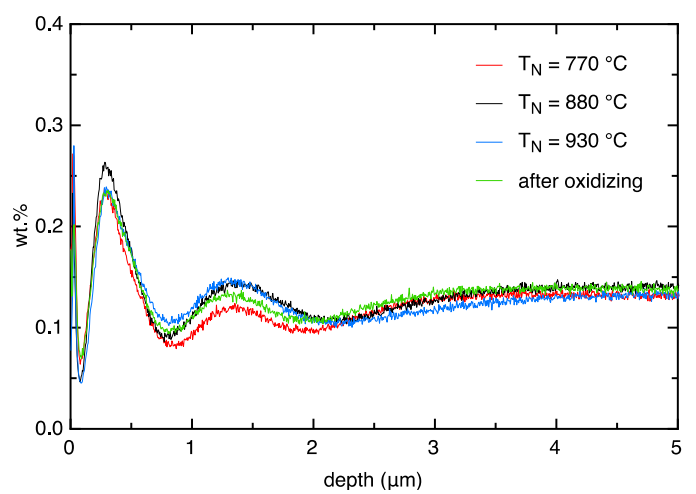

b. Chromium

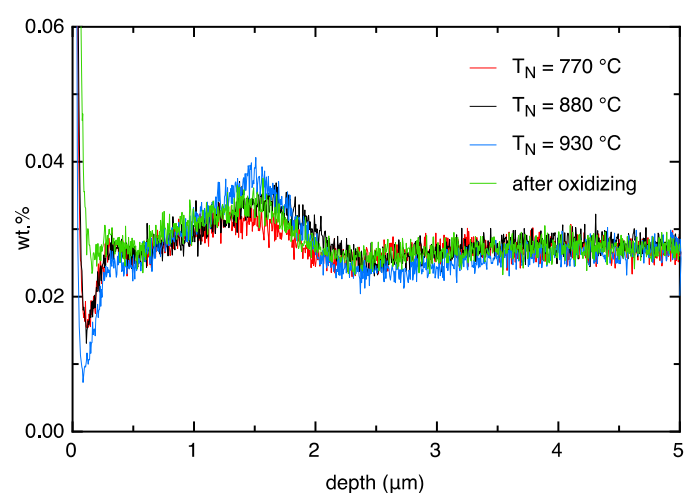

c. Aluminium

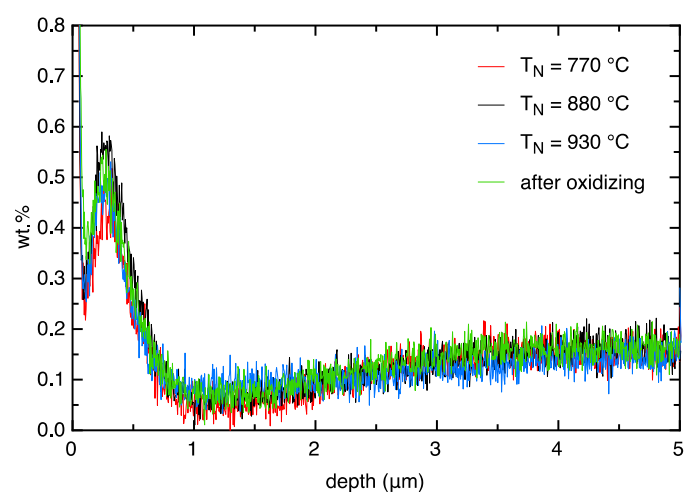

d. Manganese

Figure 8: GDOES chemical analyses of GO electrical steel. Influence of the nitriding temperature $\left(T_{N}\right)$ on (a) silicon, (b) chromium, (c) aluminium and (d) manganese in-depth content profiles. 


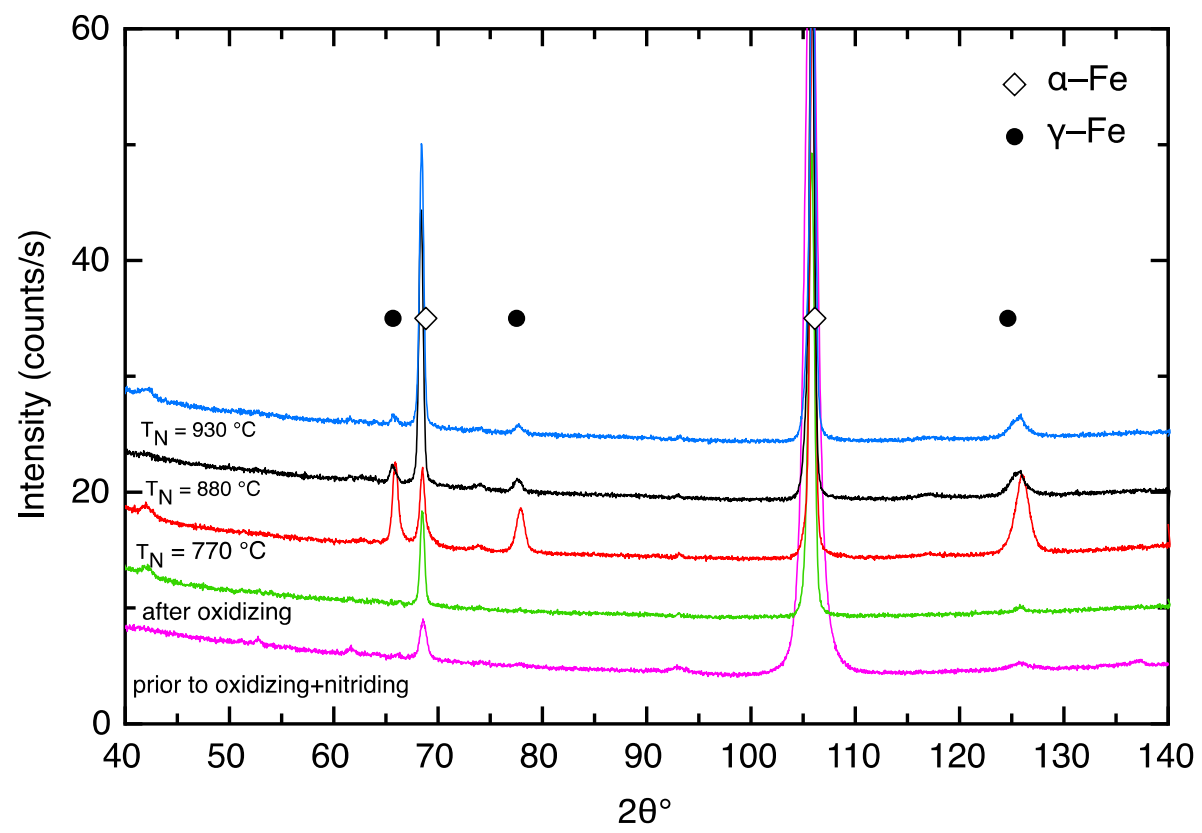

83

a. After nitriding

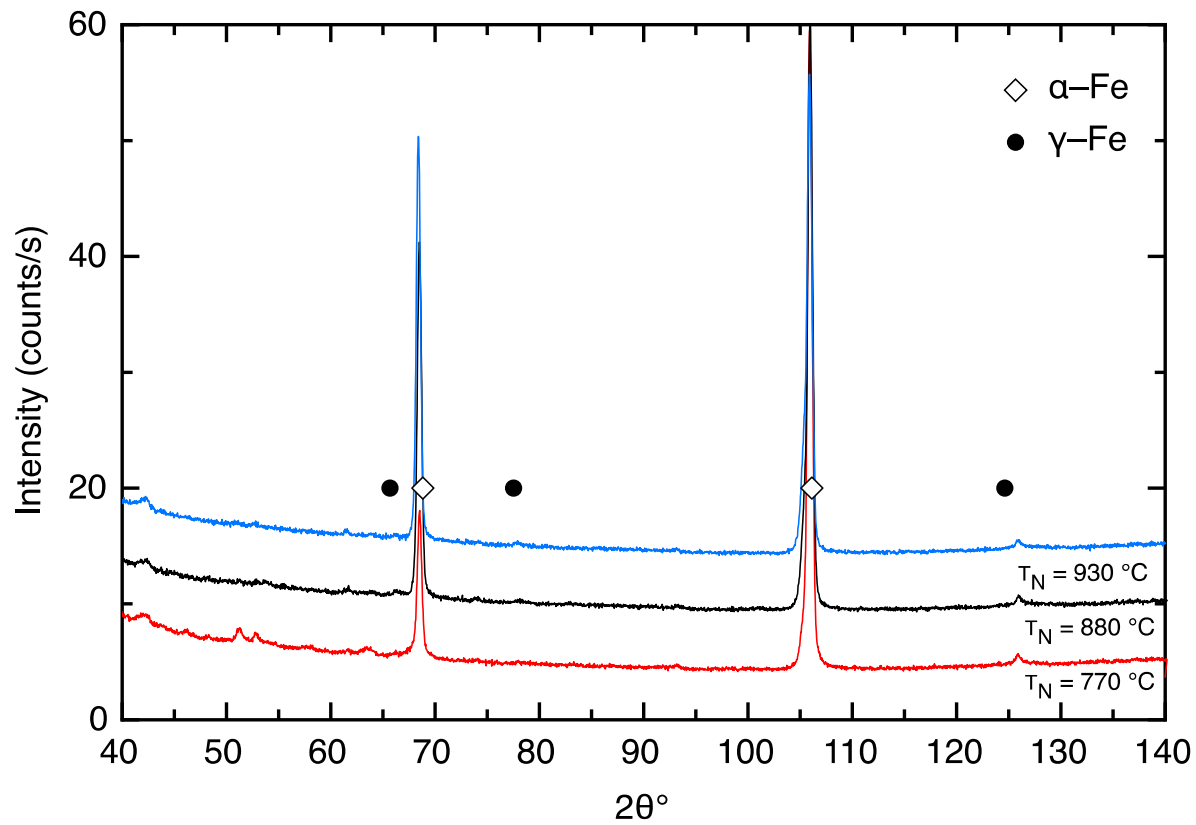

b. Tempering after nitriding

Figure 9: XRD phase analyses of GO electrical steel. Influence of the (a) nitriding temperature $\left(T_{N}\right)$ and (b) tempering after nitriding. 


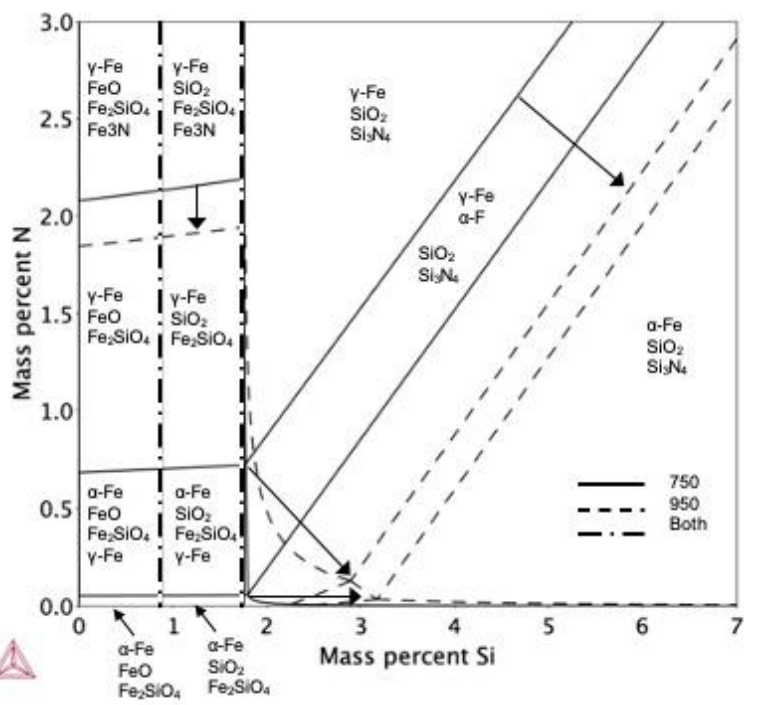

94

a.

95

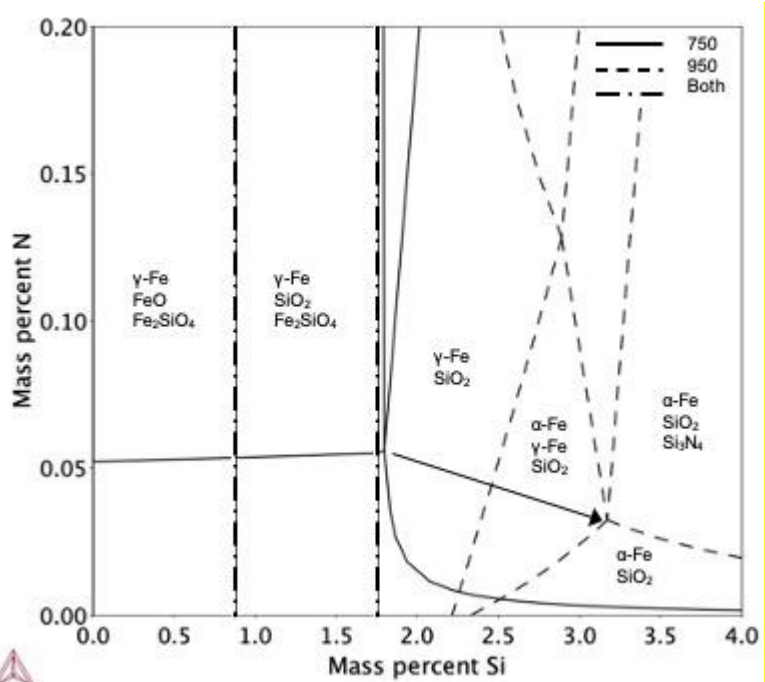

b.

Figure 10: Isopleth diagrams of Fe-Si-N-2.0wt.\%O at 750 and $950{ }^{\circ} \mathrm{C}$. (a) phase fields given for 750 ${ }^{\circ} \mathrm{C}$. (b) phase fields given for $950{ }^{\circ} \mathrm{C}$.

101

102 


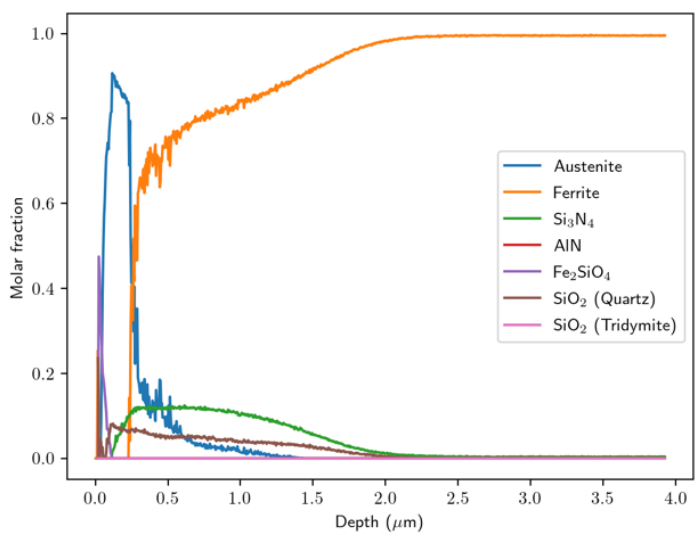

105

106

a. $770{ }^{\circ} \mathrm{C}$

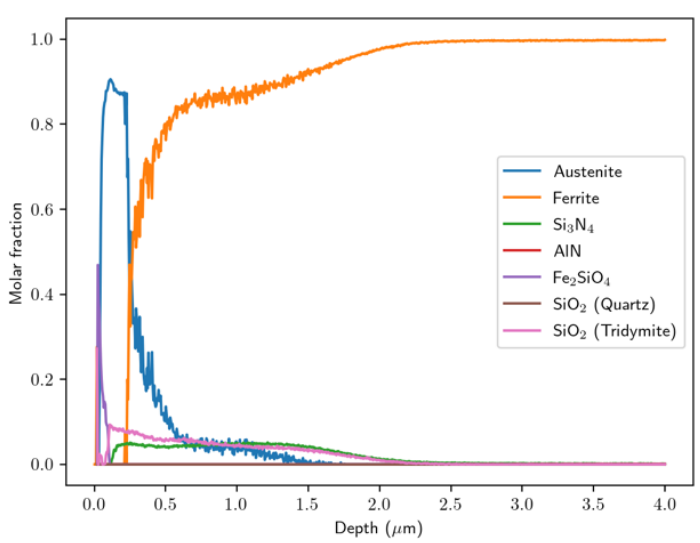

108

b. $880^{\circ} \mathrm{C}$

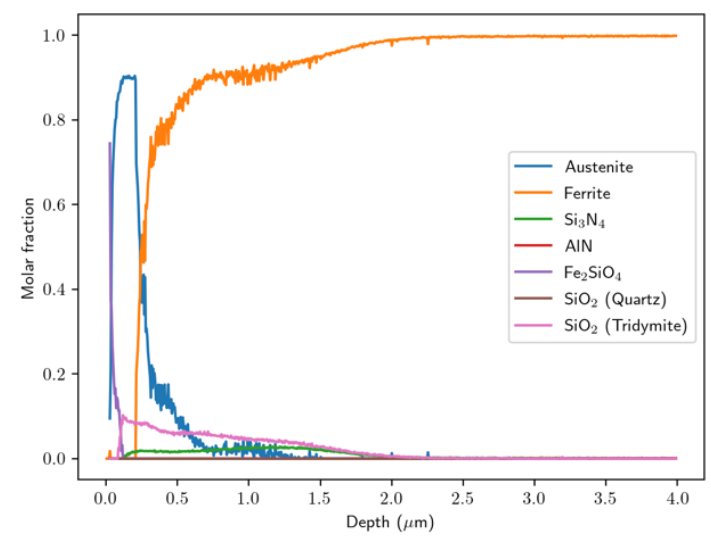

110

111

112

c. $930{ }^{\circ} \mathrm{C}$

113

Figure 11: Calculations of the phase fractions as a function of the nitrogen content in an electrical steel according to GDOES analysis of the nitrided sample at (a) 770, (b) 880 and (c) $900{ }^{\circ} \mathrm{C}$.

114

115 